\title{
Avicennia marina biomass characterization towards bioproducts
}

\author{
Saleha Almardeai, Juan-Rodrigo Bastidas-Oyanedel*, Sabeera Haris, Jens Ejbye Schmidt* \\ Khalifa University of Science and Technology, Masdar Institute, Masdar City, P.O. Box 54224, Abu Dhabi, United Arab Emirates
}

\section{A B S T R A C T}

\begin{abstract}
Avicennia marina is the only naturally occurring mangrove specie in the arid Arabian Gulf coast of the United Arab Emirates (UAE). Due to the water scarcity of this arid-region, A. marina is a precious biomass resource for the UAE that does not require fresh water for growing, and is able to grow in the Arabian Gulf high salinity conditions, over $40 \mathrm{~g} / \mathrm{kg}$. This non-fresh water lignocellulosic arid-region bioresource may be used for the production of high valuable chemicals. The objective of the present manuscript is to characterize the lignocellulosic composition of Arabian Gulf $A$. marina, as a first attempt to highlight its importance in a biobased economy in arid regions. Avicennia marina stem, leaves and pneumatophors samples were collected from two locations in the United Arab Emirates. A. marina samples were chemically characterized for sugar composition, ash content and byproducts using standardized protocols. The analysis revealed that $A$. marina arabinan, xylan, glucan and lignin composition ranges, in g/100g_TS (TS: total solids), between 1-22, 5-18, 10-31, and 21-48, respectively. The highest composition of xylan and glucan (g/100g_TS) was obtained for stems and pneumatophors, 45 and 38, respectively. Xylan and glucan are the polymeric precursors for the production of high value chemicals, e.g. furfural and hydroxymethylfurfural (HMF), respectively. Under the characterization conditions, it was obtained furfural and HMF (g/100g_TS) in the ranges of $0.05-0.42$, and $0.45-2.1$, respectively.
\end{abstract}

Keywords: Avicennia marina; Biomass characterization; Glucan; Lignocellulose; Mangrove

\section{INTRODUCTION}

Mangroves are found in 112 countries around the world covering around 160,000 km $\mathrm{km}^{2}$ approximately (Kathiresan and Bingham 2001; Mijan Uddin et al. 2014). In the United Arab Emirates (UAE), the only naturally occurring mangrove specie is Avicennia marina (EAD 2016). In the UAE mangrove forests covered area has increased from $40 \mathrm{~km}^{2}$ to $155 \mathrm{~km}^{2}$, from 2005 to 2014 (EAD 2016) thanks to plantation, public awareness and conservation efforts. Mangroves in the gulf coast of the UAE grow in high salinity conditions, over $40 \mathrm{~g} / \mathrm{kg}$ (Smith et al. 2007). The world seawater reference salinity is $35 \mathrm{~g} / \mathrm{kg}$ (Millero et al. 2008).

In Arid region, as in the UAE, where rain precipitation is scarce, e.g. $120 \mathrm{~mm}$ average annual rainfall in UAE (Böer 1997), biomass availability is limited due to the fresh water scarcity, which constrains forestry and agricultural activities
(Bastidas-Oyanedel et al. 2016). The controlled use of A. marina, as a lignocellulosic feedstock, can overcome this issue. Lignocellulose biorefinery, for the production of high value chemicals, interest has boosted in the recent years (Zhang 2008; FitzPatrick et al. 2010), where worldwide, $10^{9}$ million tonnes of lignocellulose is estimated (Alvira et al. 2010). Additionally, conservation and plantation of A. marina has environmental benefits, such as increase in fishery, biodiversity, ecotourism, protection against erosion, and feedstock (Kairo et al. 2001; Han 2003; Sato et al. 2005; Shaifullah et al. 2009).

The objective of the present study (Fig. 1) is the characterization of lignocellulosic components of A. marina leaves, stem and pneumatophors, in UAE, as a first attempt to highlight its importance in a biobased economy in arid regions, for the production of cellulose/ hemicellulose derived high value chemicals, e.g. furfural and also to create a database of local endemic plants.

\footnotetext{
${ }^{*}$ Corresponding author:

Juan-Rodrigo Bastidas-Oyanedel and Jens Ejbye Schmidt, Khalifa University of Science and Technology, Masdar Institute, Masdar

City, P.O. Box 54224, Abu Dhabi, United Arab Emirates. E-mail: jbastidas@masdar.ac.ae, jschmidt@masdar.ac.ae
}

Received: 01 August 2017; Revised: 21 September 2017; Accepted: 24 September 2017;

Published Online: 12 October 2017 


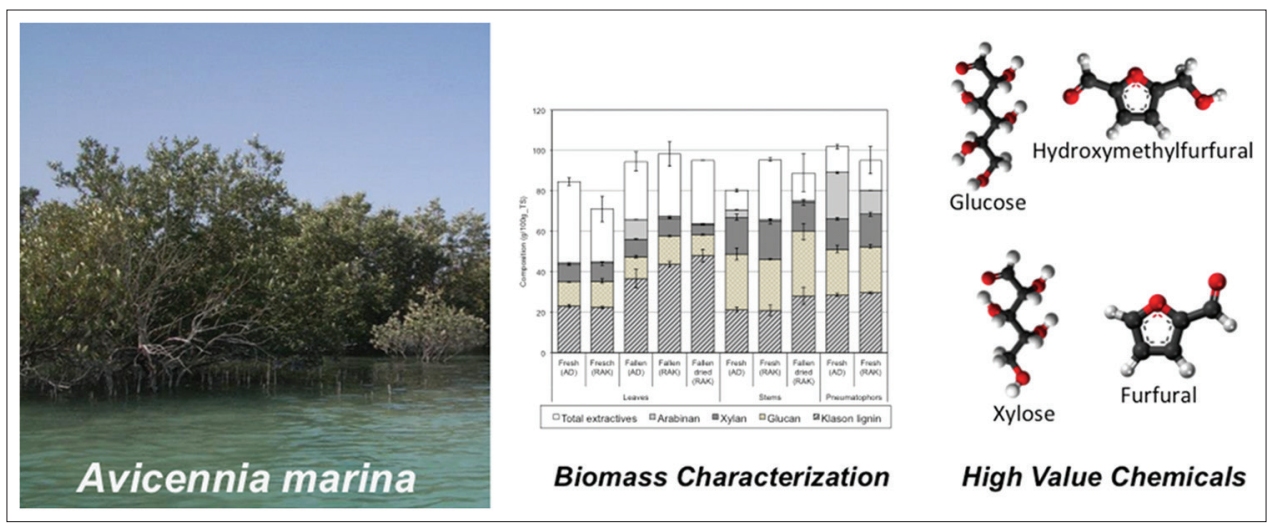

Fig 1. Scheme of the manuscript objective. Left: Avicennia marina forest in the coast of Abu Dhabi, United Arab Emirates; Center: Lignocellulosic characterization; Right: furfural and hydroxymethylfurfural, high value molecules, molecular model.

\section{MATERIALS AND METHOD}

\section{Biomass collection and preparation}

Avicennia marina biomass samples were collected from two different locations, Ras Al-Khaimah and Abu Dhabi, United Arab Emirates, according to the following coordinates $25^{\circ} 46^{\prime} 31.33^{\prime \prime} \mathrm{N} 55^{\circ} 57^{\prime} 47.98^{\prime \prime} \mathrm{E}$ and $24^{\circ} 27^{\prime} 20.58^{\prime \prime} \mathrm{N}$ $54^{\circ} 24^{\prime} 18.19^{\prime \prime} \mathrm{E}$, respectively. A. marina biomass samples consisted on: Fresh leaves; Fallen leaves; Fresh stems; Fallen stems; and Fresh pneumatophors. All the samples were washed with milliQ water, air dried at $25{ }^{\circ} \mathrm{C}$ and milled with a knife mill (IKA, $10 \mathrm{MF}$ Basic) to pass through a $2 \mathrm{~mm}$ screen. Material characterization and biomethane potential analysis where performed by triplicates for each mangrove part/location.

\section{Material characterization}

All the $A$. marina samples were quantified for total solids (TS), volatile solids (VS), total ashes, glucan, xylan, klason lignin, structural ashes, and extractives, content. TS and VS were quantified by drying a known mass of each sample at $105^{\circ} \mathrm{C}$ and $570^{\circ} \mathrm{C}$. Structural carbohydrates and lignin composition where determined by a two-step acid hydrolysis of extractive-free biomass. Biomass samples with TS content below $90 \%$ were first dried at $105^{\circ} \mathrm{C}$ for $12 \mathrm{~h}$. Then the biomass was extracted for waxes, fats, gums, tannins, sugars, starch, non-structural salts, and coloring matter using water and ethanol extraction. The extraction was performed by Soxhlet equipment. Millipore water and 96\% pure ethanol were used for the water and ethanol extraction. Extraction was followed by strong acid hydrolysis using $72 \% \mathrm{H}_{2} \mathrm{SO}_{4}$ (Sowunmi et al. 2016). The hydrolyzates were analyzed by HPLC (Agilent 1260 Infinity Bio-Inert Binary LC), using a A Hi Plex-H column (Agilent) and refractive index detector, for determination of glucose, xylose and arabinose concentration at $65^{\circ} \mathrm{C}$ with $0.005 \mathrm{M}$ $\mathrm{H}_{2} \mathrm{SO}_{4}$ as mobile phase with $0.6 \mathrm{~mL} / \mathrm{min}$ flow rate (Fang et al. 2015). Hydrothermal pretreatment, was performed at $200^{\circ} \mathrm{C}$ for 10 minutes, with $10 \% \mathrm{w} / \mathrm{w}$ dry matter loading in a Parr reactor (Parr Instrument Company) with a working volume of $1 \mathrm{~L}$. After the treatment, the reactor was cooled to $40^{\circ} \mathrm{C}$, and the pretreated material was separated by filtration into solid (fibers) and liquid fraction. Both fraction were kept at $4^{\circ} \mathrm{C}$ until analysis.

\section{Biomethane potential analysis}

For the biomethane potential analysis, Avicennia marina fallen dried stems, Ras Al-Khaimah, were used as substrate, seawater as media, and wastewater treatment sludge as inoculum. A. marina and seawater were both sampled from $\mathrm{Ras} \mathrm{Al}$ Khaimah. The sludge was sampled from Al Wathba Wastewater treatment plant, Abu Dhabi. The inoculum was incubated at $37^{\circ} \mathrm{C}$ for 2 days after collection and previous the experiments, in order to reduce its indigenous biomethane potential. Seawater $\mathrm{pH}$ was measured using commercially available probes. Seawater salinity was determined drying a known mass of sample at $105^{\circ} \mathrm{C}$ and $570^{\circ} \mathrm{C}$. Seawater salinity was $43.2 \pm 0.1 \mathrm{~g} / \mathrm{kg}$ and a $\mathrm{pH}$ was 7.29. Biomethane potential experiments were conducted in triplicates at $37^{\circ} \mathrm{C}$ in serum bottles with $115 \mathrm{ml}$ liquid volume and $212 \mathrm{ml}$ headspace. The experiment was conducted using $1.09 \mathrm{gVSmangrove} / \mathrm{gVSinoculum}$ and an inoculum concentration of $11.4 \mathrm{~g} / \mathrm{L}$. After loading the serum bottles with the mangrove sample, inoculum and seawater, their headspace was then flushed with a gas mixture of $80 \% \mathrm{~N}_{2}$ and $20 \% \mathrm{CO}_{2}$ to ensure anaerobic conditions and prevent $\mathrm{pH}$ changes in the liquid phase, during the flushing, (Sowunmi et al. 2016). The serum bottles were immediately sealed with with thick rubber septum (chlorobutyle rubber, Apodan Nordic, Denmark) after flushing to maintain anaerobic conditions. Gas samples of $0.5 \mathrm{~mL}$ were collected from the serum bottle headspaces using a $1 \mathrm{~mL}$ pressure lock valve syringe. Biomethane was quantified by gas chromatography (GC SRI Instrument, SRI 8610C with 3" Silica Gel column) equipped with a flame ionization detector (FID). 


\section{RESULTS AND DISCUSSION}

The error bars in Figures, presented in this section, are shown as the standard deviation of the triplicated experimental data, including the propagation of error.

\section{Determination of dry matter (total solids) and ash in} A. marina samples

Fig. 2 shows the total solids as the sum of volatile solids and ashes. All samples contain an average of $70 \%$ volatile solids. Leaves samples contain the highest ash values, in average $20 \%$, and they have the less moisture content, $10 \%$. The volatile solids content indicate the organic fraction of the biomass, which can be used for the production of high value chemicals (Zhang 2008; FitzPatrick et al. 2010), and bioenergy as biogas (Bastidas-Oyanedel et al. 2016).

\section{Determination of Klason lignin and oligosaccharides in biomass}

Fig. 3 presents A. marina biomass composition as total extractives, arabinan, xylan, glucan and klason lignin. In general, there is no significant difference between samples collected from Ras Al-Khaimah and from Abu Dhabi. Stem and pneumatophors samples contain the highest sugar content. Arabinan content in stems is low with an average of 1.6 g_arabinan/100g_TS, while its content is considerably high, above $11 \mathrm{~g}$ _arabinan $/ 100 \mathrm{~g}_{-}$ TS in pneumatophors. The glucan and xylan average composition in both stems and pneumatophors was 26 and $16.4 \mathrm{~g} / 100 \mathrm{~g} \_$TS, respectively. Glucan and xylan are the precursors for the production of high value chemicals, e.g. furfural, hydroxymethylfurfural (HMF), and levulinic acid, by thermochemical processes (Alvira et al. 2010) or glucaric acid by fermentation processes (Gupta et al. 2016a). Characterization of other arid region lignocellulosic biomass, Phoenix dactylifera and Salicornia bigelovii, has reported glucan and xylan values of 41.2 g_glucan/100 gTS, 21.5 g_xylan/100_gTS and 9.1 g_glucan/100_gTS, 7.7 g_xylan/100_gTS, respectively (Ashraf et al. 2016; Cybulska et al. 2014).

The total extractives, which are the main constituent of the leaves, can be compounds of high market value such as naphthoquinonoes (anticarcinogenic activity), betain (dietary supplement), iridoid glucosides, triacontane, trimethylglycine, and bioactive lipids (Popp 1984; Konig and Rimpler 1985; Wu et al. 2008; Ramadan et al. 2009; Liebezeit 2012).

Fig. 4 shows the concentration of acetic acid, furfural and HMF produced during the thermochemical hydrolysis. These compounds are considered bioethanol fermentation inhibitors formed during the pentose and hexose degradation (Jönsson and Martín 2015). Nevertheless, furfural and HMF are amongst the 10 most valuable bioproducts listed by the US Department of Energy and they are a highly potential renewable chemical feedstock for the production of valuable chemicals and biofuels (Agustina et al. 2013; Cai et al. 2013). In fact, production of furfural from cellulose can be commercially more attractive

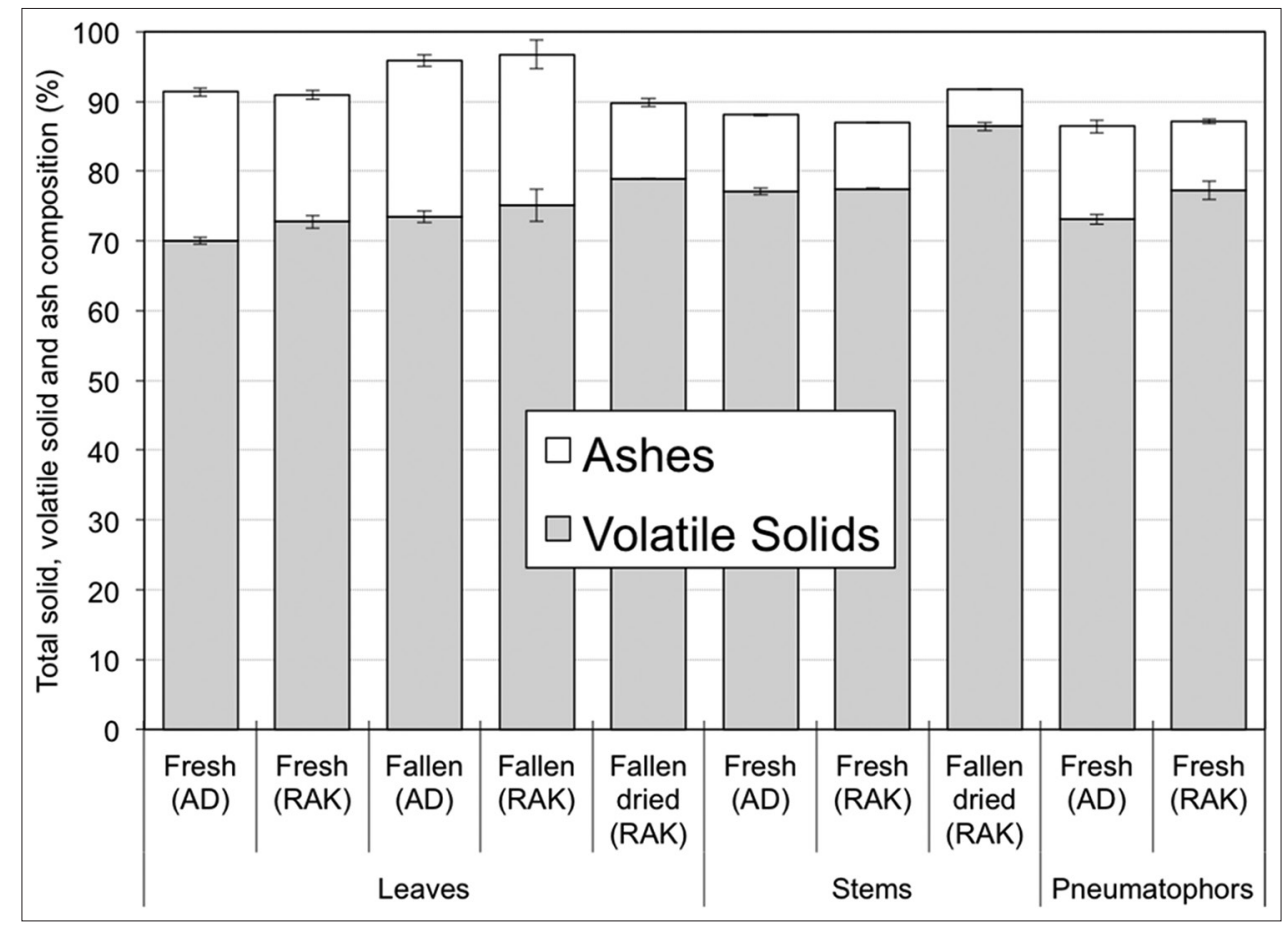

Fig 2. A. marina biomass composition as total solids (TS) expressed as volatile solids (VS) and ashes. 


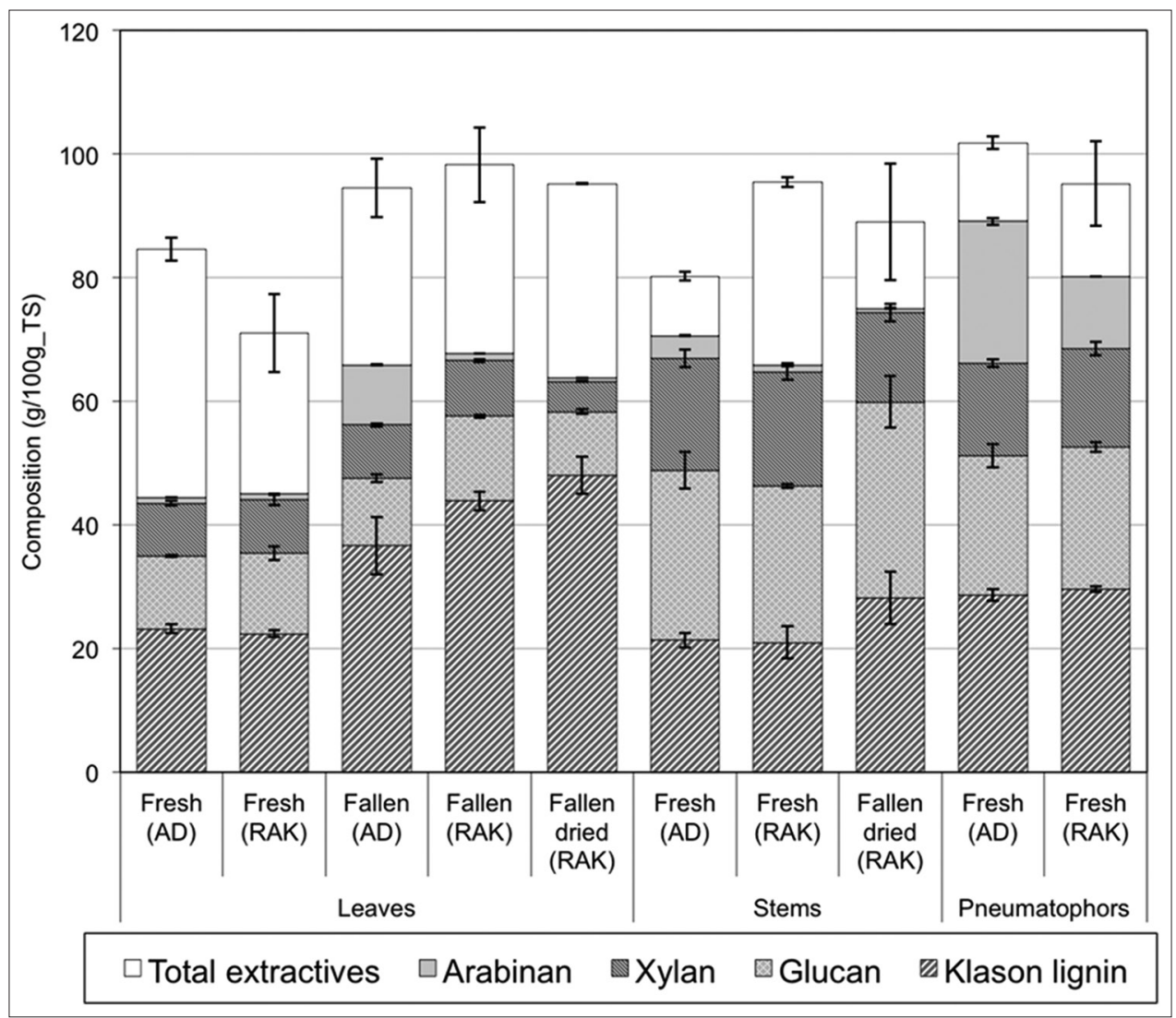

Fig 3. A. marina biomass composition as total extractives, arabinan, xylan, glucan, and klason lignin.

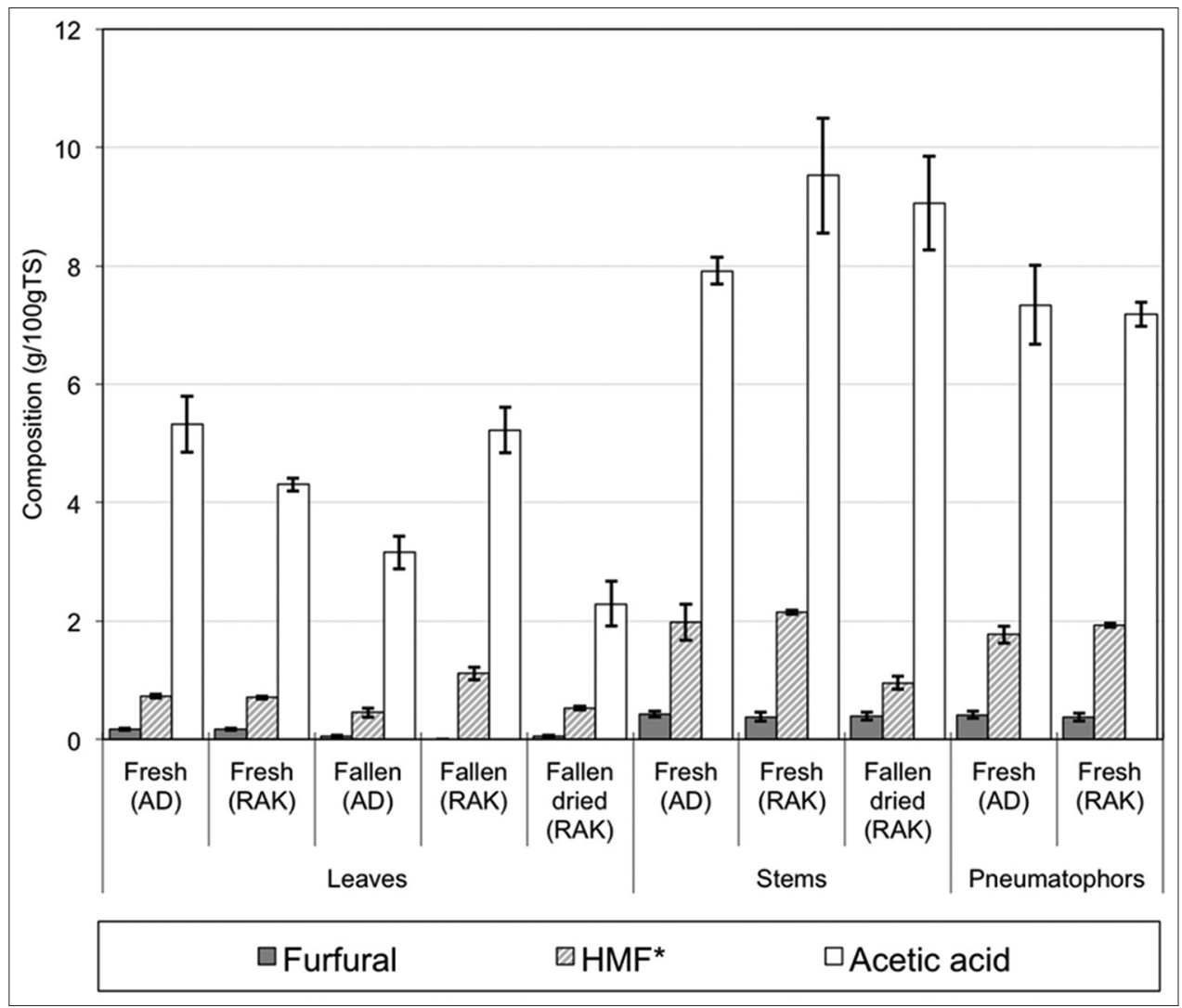

Fig 4. A. marina biomass acid hydrolysis products at $121^{\circ} \mathrm{C}$ with $72 \%$ sulfuric acid. ( ${ }^{*}$ Hydroxymethyl Furfural). 
than bioethanol by yeast fermentation. Moreover, HMF can be converted to 2,5-dimethylfuran (DMF), which has 40 percent higher energy density than ethanol (Cai et al. 2013).

Furthermore, Anaerobic digestion of $A$. marina biomass and/or residues of its processing is possible, even using UAE Arabian Gulf sea water (Bastidas-Oyanedel et al. 2016), which can contribute to the production of biogas. Fig. 5 shows the cumulative biomethane produced from $A$. marina, using Arabian Gulf seawater (43.2 $\pm 0.1 \mathrm{~g} / \mathrm{kg}$ salinity).

As per this study, the use of seawater is possible in the production of biomethane. This result will open new doors for research related to biofuel and chemical production based on seawater lignocellulosic biomass. The substitution of fresh water by seawater is economically and environmentally important for arid regions, as is the case of the MENA region, where from its 20 countries, 14 are in absolute water scarcity, 4 in chronic water scarcity and two in occasional local water stress (Bastidas-Oyanedel et al. 2016). Therefore, lignocellulosic biomass based activities in arid regions main challenge is to minimize the use of freshwater. In this context $A$. marina is promising biomass for seawater biorefinery, as it is adapted to UAE sea water salinity conditions.

The sustainable utilization of mangrove forest in coastal arid regions has not only the benefits of producing lignocellulosic biomass without freshwater, but also aims at the conservation and plantation of $A$. marina in the UAE because of the biodiversity it hosts. Apart from fishes and crustacean biomass (Kathiresan and Bingham 2001; Han 2003), mangroves are a habitat to other living organisms, which have biotechnological potentials (Kathiresan and Bingham 2001). Polyalkanoates producing bacteria

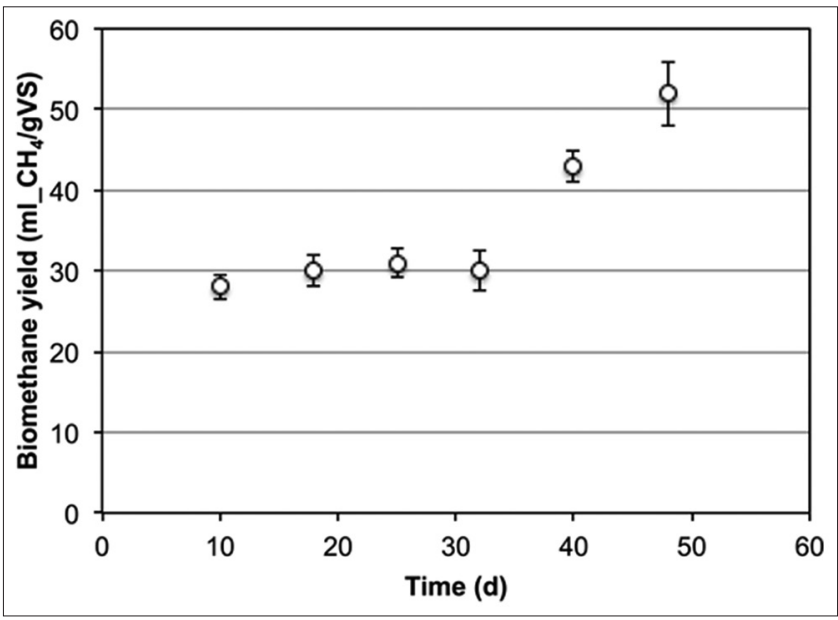

Fig 5. Biomethane potential of Avicennia marina fallen dried stem, Ras Al-Khaimah, at seawater conditions over an incubation period of 48 days. Seawater, $43.2 \mathrm{~g} / \mathrm{kg}$ salinity. The substrate over inoculum ratio is $1.09 \mathrm{gVS}$ _Avicennia marina/gVS_inuculm. VS: volatile solids.
(Moorkoth and Nampoothiri 2016), and terpenoids producing bacteria (Mitra et al. 2008) has been isolated from mangrove soil. Enzymes, antimicrobials, and biopesticides have been isolated from mangrove fungi (Cheng et al. 2009). Long-chain omega- 3 fatty acids producing microalgae have also been found in mangrove forests (Gupta et al. 2016b). Anyhow, it is strongly emphasized that any mangrove-based lignocellulosic biomass exploitation must be only applied in mangrove ecosystems where conservation efforts are well implemented, or refrain otherwise.

\section{CONCLUSIONS}

The chemical composition of Avicennia marina biomass: leaves, stem and pneupatophors, have been quantified. Samples were collected from two locations in the United Arab Emirates (UAE), Ras Al Khaima and Abu Dhabi. The results showed no significant variation between these two locations. Average volatile solids for all the biomasses was $70 \%$. Higher content of sugars, arabinan, xylan and glucan, was found in stems and pneumatophors. The highest extractives content was found in leaves. The present study highlights the importance of $A$. marina in the UAE as a lignocellulose resource, for biorefinery processes, overcoming the water scarcity issue of arid regions.

\section{ACKNOWLEDGEMENTS}

The authors would like to acknowledge the financial support from Masdar Institute of Science and Technology, to help fulfill the vision of the late President Sheikh Zayed Bin Sultan Al Nahyan for sustainable development and empowerment of the United Arab Emirates and humankind, funding project 2GBIONRG (12KAMA4).

\section{Authors' Contributions}

Saleha Almardeai: Experimental design, experimental work, data analysis, manuscript preparation.

Juan-Rodrigo Bastidas-Oyanedel: Scientific question, experimental design, experimental data analysis, mass balances, manuscript preparation, critical review.

Sabeera Haris: critical review of the manuscript

Jens Ejbye Schmidt: Scientific question, critical review of the manuscript

\section{REFERENCES}

Agustina, D., S. Kumagai, M. Nonaka and K. Sasaki. 2013. Production of 5-hydroxymethyl furfural from sugarcane bagasse under hot compressed water. Procedia Earth Planet Sci. 6: 441-447. 
Alvira, P., E. Tomás-Pejó, M. Ballesteros and M. J. Negro. 2010. Pretreatment technologies for an efficient bioethanol production process based on enzymatic hydrolysis: A review. Bioresour. Technol. 101: 4851-4861.

Ashraf, M., C. Fang, T. Bochenski, I. Cybulska, A. Alassali, A. Sowunmi, R. Farzanah, G. P. Brudecki, T. Chaturvedi, S. Haris, J. E. Schmidt and M. H. Thomsen. 2016. Estimation of bioenergy potential for local biomass in the United Arab Emirates. Emirates J. Food Agric. 28: 99-106.

Bastidas-Oyanedel, J. R., C. Fang, S. Almardeai, U. Javid, A. Yousuf and J. E. Schmidt. 2016. Waste biorefinery in arid/semi-arid regions. Bioresour. Technol. 215: 21-28.

Böer, B. 1997. An introduction to the climate of the United Arab Emirates. J. Arid Environ. 35: 3-16.

Cai, C. M., T. Zhang and C. E. Wyman. 2013. Integrated furfural production as a renewable fuel and chemical platform from lignocellulosic biomass. J. Chem. Technol. Biotechnol. 89: 2-10.

Cheng, Z. S., J. H. Pan, W. C. Tang, Q. J. Chen and Y. C. Lin. 2009. Biodiversity and biotechnological potential of mangroveassociated fungi. J. Forestry Res. 20: 63-72.

Cybulska, I., T. Chaturvedi, G. P. Brudecki, Z. Kadar, A. S. Meyer, R. M. Baldwin and M. H. Thomsen. 2014. Chemical characterization and hydrothermal pretreatment of Salicornia bigelovii straw for enhanced enzymatic hydrolysis and bioethanol potential. Bioresour. Technol. 153: 165-172.

EAD. 2016. Status of Mangroves in Abu Dhabi-biodiversity Annual Report 2014. Environmental Agency-Abu Dhabi.

Fang, C., M. H. Thomsen, G. P. Brudecki, I. Cybulska, C. G. Frankaer, J. R. Bastidas-Oyanedel and J. E. Schmidt. 2015. Seawater as alternative to freshwater in pretreatment of date palm residues for bioethanol production in coastal and/or arid areas. Chem. Sus Chem. 8: 3823-3831.

Fitzpatrick, M., P. Champagne, M. F. Cunningham and R. A. Whitney. 2010. A biorefinery processing perspective: Treatment of lignocellulosic materials for the production of value-added products. Bioresour. Technol. 101: 8915-8922.

Gupta, A., M. A. Hicks, S. P. Manchester and K. L. J. Prather. 2016a. Porting the synthetic D-glucaric acid pathway from Escherichia coli to Saccharomyces cerevisiae. Biotechnol. J. 11: 1201-1208.

Gupta, A., D. Singh, A. R. Byreddy, T. Thyagarajan, S. P. Sonkar, A. S. Mathur, D. K. Tuli, C. J. Barrow and M. Puri. 2016b. Exploring omega-3 fatty acids, enzymes and biodiesel producing thraustochytrids from Australian and Indian marine biodiversity. Biotechnol. J. 11: 345-355.

Han, W. D. 2003. Present status and conservation strategies of mangrove resource in Guangdong, P.R. China. J. Forestry Res. 14: 151-154.

Jönsson, L. J. and C. Martín. 2015. Pretreatment of lignocellulose: Formation of inhibitory by-products and strategies for minimizing their effects. Bioresour. Technol. 199: 103-112.

Kairo, J. G., F. Dahdouh-Guebas, J. Bosire and N. Koedam. 2001. Restoration and management of mangrove systems-a lesson for and from the East African region. South Afr. J. Bot. 67: 383-389.

Kathiresan, K. and B. L. Bingham. 2001. Biology of mangroves and mangrove ecosystems. Adv. Mar. Biol. 40: 81-251.

Konig, G. and H. Rimpler. 1985. Iridoid glucosides in Avicennia marina. Phytochemistry. 24: 1245-1248.

Liebezeit, G. 2012. Natural products chemistry of the mangrove species Avicennia spp. - Review and new data. Nat. Prod. Indian J. 8: 10-20.

Mijan-Uddin, S.M., A. T. M. R. Hoque and S. A. Abdullah. 2014. The changing landscape of mangroves in Bangladesh compared to four other countries in tropical regions. J. Forestry Res. 25: 605-611

Millero, F. J., R. Feistel, D. G. Wright and T. J. McDougall. 2008. The composition of Standard Seawater and the definition of the reference-composition salinity scale. Deep Sea Res. Part I Oceanogr. Res. Pap. 55: 50-72.

Mitra, A., S. C. Santra and J. Mukherjee. 2008. Distribution of actinomycetes, their antagonistic behaviour and the physicochemical characteristics of the world's largest tidal mangrove forest. Appl. Microbiol. Biotechnol. 80: 685-695.

Moorkoth, D. and K. M. Nampoothiri. 2016. Production and characterization of poly(3-hydroxy butyrate-co-3 hydroxyvalerate) (PHBV) by a novel halotolerant mangrove isolate. Bioresour. Technol. 201: 253-260.

Popp, M. 1984. Chemical composition of Australian mangroves II. Low molecular weight carbohydrates. Z. Pflanzenphysiol. 113: 411-421.

Ramadan, M. F., M. M. A. Amer, H. T. Mansour, K. M. Wahdan, R. M. El-Sayed, S. El-Sanhoty and W. A. El-Gleel. 2009. Bioactive lipids and antioxidant properties of wild Egyptian Pulicaria incise, Diplotaxis harra, and Avicennia marina. J. Verbrauch. Lebensm. 4: 239.

Sato, G., A. Fisseha, S. Gebrekiros, H. A. Karim, S. Negassi, M. Fischer, E. Yemane, J. Teclemariam and R. Riley. 2005. A novel approach to growing mangroves on the coastal mud flats of Eritrea with the potential for relieving regional poverty and hunger. Wetlands. 25: 776-779.

Shaifullah, K. M., S. M. S. Haque, M. Sujauddin and S. Karmakar. 2009. Coastal afforestation effects on soil properties at Hatiya in Bangladesh. J. Forestry Res. 20: 243-248.

Smith, R., A. Purnama and H. H. Al-Barwani. 2007. Sensitivity of hypersaline Arabian Gulf to seawater desalination plants. Appl. Math. Model. 31: 2347-2354.

Sowunmi, A., R. M. Mamone, J. R. Bastidas-Oyanedel and J. E. Schmidt. 2016. Biogas potential for electricity generation in the Emirate of Abu Dhabi. Biomass Convers. Biorefin. 6: 39-47.

Wu, J., Q. Xiao, J. Xu, M. Y. Li, J. Y. Pan and M. H. Yang. 2008. Natural products from true Mangrove flora: Source, chemistry and bioactivities. Nat. Prod. Rep. 25: 955-981.

Zhang, Y. H. P. 2008. Reviving the carbohydrate economy via multiproduct lignocellulose biorefineries. J. Ind. Microbiol. Biotechnol. 35: 367-375. 